\title{
Distribution of cortical granules and meiotic maturation of canine oocytes in bi-phasic systems
}

\author{
Maricy Apparicio A,C, Giuliano Q. Mostachio ${ }^{\mathrm{A}}$, Tathiana F. Motheo ${ }^{\mathrm{A}}$, \\ Aracelle E. Alves ${ }^{\mathrm{A}}$, Luciana Padilha ${ }^{\mathrm{A}}$, Eliandra A. Pires-Butler ${ }^{\mathrm{A}}$, \\ Paula A. P. Savi ${ }^{\mathrm{A}}$, Ricardo A. R. Uscategui ${ }^{\mathrm{A}}$, Gaia C. Luvoni ${ }^{\mathrm{B}}$ \\ and Wilter R. R. Vicente ${ }^{\mathrm{A}}$ \\ A UNESP - Univ Estadual Paulista, Jaboticabal Campus, Departamento de Medicina Veterinária \\ Preventiva e Reprodução Animal, Via de Acesso Prof. Paulo Donato Castellane, \\ s/n, 14884-900, Jaboticabal-SP, Brazil. \\ ${ }^{B}$ Dipartimento di Scienze Veterinarie per la Salute, la Produzione Animale e la Sicurezza \\ Alimentare, Università degli Studi di Milano, Via Celoria 10, 20133 Milano, Italy. \\ ${ }^{\mathrm{C} C o r r e s p o n d i n g ~ a u t h o r . ~ E m a i l: ~ m a r i c y a p @ f c a v . u n e s p . b r ~}$
}

\begin{abstract}
The aim of this study was to evaluate the influence of different bi-phasic systems with gonadotrophins and steroids on in vitro maturation rates of oocytes obtained from bitches at different reproductive stages (follicular, luteal, anoestrous). In System A (control) oocytes were matured for $72 \mathrm{~h}$ in base medium (BM) with $10 \mathrm{IU} \mathrm{mL}^{-1}$ human chorionic gonadotrophin (hCG), $1 \mu \mathrm{g} \mathrm{mL}^{-1}$ progesterone (P4) and $1 \mu \mathrm{g} \mathrm{mL}^{-1}$ oestradiol (E2); in bi-phasic System B oocytes were matured for $48 \mathrm{~h}$ in BM with hCG and for $24 \mathrm{~h}$ in BM with P4; in bi-phasic System Coocytes were matured for $48 \mathrm{~h}$ in BM with hCG, P4 and E2, and for $24 \mathrm{~h}$ in BM with P4; in System D, oocytes were cultured in BM without hormonal supplementation. Data were analysed by ANOVA. There was a positive effect of the bi-phasic systems on germinal vesicle breakdown, metaphase I and metaphase II rates, irrespective of reproductive status $(P<0.05)$. Bi-phasic systems were also beneficial for cortical granule distribution (an indication of cytoplasmic maturation) and its relationship to nuclear status: $74.5 \%$ of the oocytes cultured in System B and $85.4 \%$ of those cultured in System C presented both nuclear and cytoplasmic maturation $(P<0.001)$. The stage of the oestrous cycle did not influence maturation rates.
\end{abstract}

Additonal keywords: hormones, in vitro maturation.

Received 21 January 2014, accepted 13 March 2014, published online 28 April 2014

\section{Introduction}

In several species, such as cattle and cats, in vitro reproduction techniques have been successfully used for the production of offspring. In canids, the efficiency of these techniques is limited and no offspring have been produced. This may be attributed to the deficient maturation media employed up to now and to the peculiar reproductive physiology of the dog.

Bitch oocytes are ovulated without being ready to be fertilised (i.e. while still immature) and therefore, maturation must occur in the oviduct within two to five days after the LH peak (Tsutsui 1989). In the preovulatory follicle, canine oocytes are exposed to high concentrations of progesterone (P4) and oestradiol (E2), and different concentrations of gonadotrophins are present in the pre- and post-ovulatory environment, i.e. oviduct, where full maturation occurs (Willingham-Rocky et al. 2003; De los Reyes et al. 2005). These characteristics, together with other particular features related to the endocrine events of each phase of the cycle are factors that have contributed towards the limitations of the in vitro maturation technique for this species.
For this reason, attempts have been made to identify the factors involved in the resumption and progression of in vivo meiosis, so that adaptations to laboratory environments can be made and improvements in cultural conditions can be achieved.

However, most of the protocols that have been tested for IVM of canine oocytes were modified from those used in other mammals and so did not take into account species-specific requirements. Addition of hormones to the maturation medium provides an environment that is more appropriate and more similar to in vivo conditions, and for canine oocyte maturation the pre- and post-ovulatory environments to which the oocytes are exposed in vivo should be mimicked in vitro (Luvoni et al. 2005). Up to now only a few studies considered the dynamics of the hormonal environment during in vivo maturation of canine oocytes.

De los Reyes et al. (2005) first suggested that maturation could be affected by the duration of hormonal exposure; in their study oocytes exposed to human chorionic gonadotrophin (hCG) during only the first $48 \mathrm{~h}$ presented higher metaphase II 
(MII) rates compared with those cultured in a medium with hCG for the whole period (96h). These results prompted to the investigation of a bi-phasic system using a combination of different hormones; the results of a pilot study indicated that oocytes matured in sequential media with hormones presented higher MII compared with those exposed to hormones in a continuous way (Apparicio et al. 2009). Recently, this evidence was confirmed by a study of Evecen et al. (2011), in which metaphase I (MI)+MII rates were higher among oocytes cultured in sequential media than those matured in the traditional way. However, in the aforementioned studies only nuclear maturation was evaluated and no information was available on cytoplasmic changes during culture.

During progression of meiosis, dog oocytes undergo cytoskeletal modifications similar to those observed in other mammalian species (de Lesegno et al. 2008); there is an extensive redistribution of intracellular organelles such as mitochondria and cortical granules (Cran and Esper 1990). Thus, the dynamic of cortical granules (CG) changes during oocyte development, and the CG staining pattern has been used in different species as an indicator of cytoplasmic maturation (Carneiro et al. 2002; Takano et al. 2002; Liu et al. 2005; Padilha et al. 2014). In the $\mathrm{dog}$, there is only one report that investigates the relationship between cortical granule distribution and chromatin configuration during in vitro maturation through $\mathrm{CG}$ staining using Hoescht-fluorescein isothiocyanate-conjugated Lens culinaris agglutinin (FITC-LCA; Apparicio et al. 2011).

Thus, the aim of the present study was to investigate whether the use of a bi-phasic system with a combination of steroids and gonadotrophins would improve in vitro maturation rates and would promote a synchronous progression of nuclear and cytoplasmic maturation of canine oocytes retrieved at different stages of the oestrous cycle.

\section{Materials and methods}

All chemicals in this study were purchased from Sigma-Aldrich Chemical Co. (St Louis, MO, USA) unless otherwise stated.

\section{Ovaries and collection of oocytes}

Ovaries were obtained from 36 healthy adult domestic bitches (1-7 years old) of different breeds that underwent ovariohysterectomy. The bitches were classified into groups based on stage of the oestrous cycle (12 bitches per group): follicular (FOL, proestrus or oestrus), luteal (LUT, diestrus) or anoestrus (ANE). The distribution into these stages was determined through a combination of vaginal cytology (Feldman and Nelson 1996), ovarian morphology (Otoi et al. 2001) and blood serum progesterone concentrations (radioimmunoassay kit, Coat-a-Count; Diagnostic Product Corp, Los Angeles, CA, USA).

After removal, the ovaries were placed immediately into physiological saline at $37^{\circ} \mathrm{C}$ and transported to the laboratory within $1 \mathrm{~h}$. The ovaries were removed and washed free of blood in fresh phosphate-buffered saline (PBS) supplemented with 5\% fetal calf serum (FCS) at $37^{\circ} \mathrm{C}$. Cumulus-oocyte complexes (COC) were released by slicing the ovarian cortex with a scalpel blade and graded according to the criteria reported by Hewitt and England (1997). Only COCs of Grade 1 (darkly granulated cytoplasm and completely surrounded by three or more compact cumulus cell layers) were selected for culture and evaluated. Prior to transfer to maturation medium, COCs were washed three times in Hepes-buffered medium 199.

\section{In vitro maturation of oocytes}

Oocytes from each group (FOL, LUT and ANE) were randomly allocated to four different culture systems with the base medium (BM) consisting of medium 199 (Earle's salt, buffered with $25 \mathrm{mM}$ Hepes; Vitrocell, Campinas, Brazil) with antibiotics $\left(100000 \mathrm{IU} \mathrm{mL}^{-1}\right.$ penicillin $\mathrm{G}$ sodium $+100 \mathrm{mg} \mathrm{mL}^{-1}$ streptomycin sulfate; Vitrocell, Campinas, Brazil), supplemented with $10 \%$ fetal bovine serum (FBS), $2.2 \mathrm{mg} \mathrm{mL}^{-1}$ sodium bicarbonate and $20 \mu \mathrm{L} \mathrm{mL}^{-1}$ pyruvic acid. The systems were as follows: in System A (control) oocytes were matured for $72 \mathrm{~h}$ in BM with $10 \mathrm{IU} \mathrm{mL}^{-1} \mathrm{hCG}, 1 \mu \mathrm{g} \mathrm{mL}^{-1} \mathrm{P} 4$ and $1 \mu \mathrm{g} \mathrm{mL}^{-1} \mathrm{E} 2$; in bi-phasic System B oocytes were matured for $48 \mathrm{~h}$ in BM with hCG and for an additional $24 \mathrm{~h}$ in BM with P4; in bi-phasic System C oocytes were matured for $48 \mathrm{~h}$ in $\mathrm{BM}$ with hCG, $\mathrm{P} 4$ and $\mathrm{E} 2$, and for an additional $24 \mathrm{~h}$ in BM with $\mathrm{P} 4$; in System D, oocytes were culture in BM with no hormonal supplementation. In Systems B and C hormones were supplemented at the same concentration as in System A.

Oocytes were incubated for $72 \mathrm{~h}$ in 4 -well dishes (Nunclon; Nunc, Roskilde, Denmark) containing $500 \mu \mathrm{L}$ of maturation medium per well, each of which contained not more than 30 COCs. The cultures were performed at $38^{\circ} \mathrm{C}$ in a humidified atmosphere of $5 \% \mathrm{CO}_{2}$ in air.

\section{Assessment of oocyte maturation}

At the end of the culture period $(72 \mathrm{~h})$, oocytes were removed from the drops and transferred to PBS containing $0.2 \%$ hyaluronidase for $5 \mathrm{~min}$ and the cumulus cells were subsequently removed by repeated pipetting. Oocytes were stained with FITC-LCA for cortical granule distribution and Hoechst 33342 for chromatin configuration as previously described (Apparicio et al. 2011). Briefly, cumulus-free COCs were transferred into a $70-\mu \mathrm{L}$ drop containing $0.5 \%$ pronase-PBS solution. As soon as the zona pellucida could no longer be seen under the stereomicroscope, oocytes were fixed in 3\% paraformaldehyde (Merck and Co. Inc., Whitehouse Station, NJ, USA) in PBS for $30 \mathrm{~min}$ at room temperature and then incubated overnight at $4^{\circ} \mathrm{C}$ in blocking solution (BS; PBS containing $1 \mathrm{mg} \mathrm{mL}^{-1}$ bovine serum albumin (BSA), $100 \mathrm{mM}$ glycine and $0.2 \%$ sodium azide). The oocytes were permeabilised with $0.1 \%$ Triton X-100 (USB, Cleveland, OH, USA) in BS for $8 \mathrm{~min}$ at $38^{\circ} \mathrm{C}$ and then incubated in $10 \mu \mathrm{g} \mathrm{mL}^{-1}$ FITC-LCA in BS for $15 \mathrm{~min}$. Following three washes in BS, oocytes were stained with $10 \mu \mathrm{g} \mathrm{mL}^{-1}$ Hoechst 33342 in BS for $8 \mathrm{~min}$, washed again, mounted on slides and viewed under an epifluorescent microscope (330-385 and 420-490 nm; at a magnification of $200-400 \times$ ). For nuclear maturation, oocytes were classified according to chromatin configuration as germinal vesicle $(\mathrm{GV})$ stage, germinal vesicle breakdown (GVBD), MI stage, MII stage and degenerated or unidentifiable oocytes (D/NI) when the nuclear stage was not identifiable or when the chromatin was 


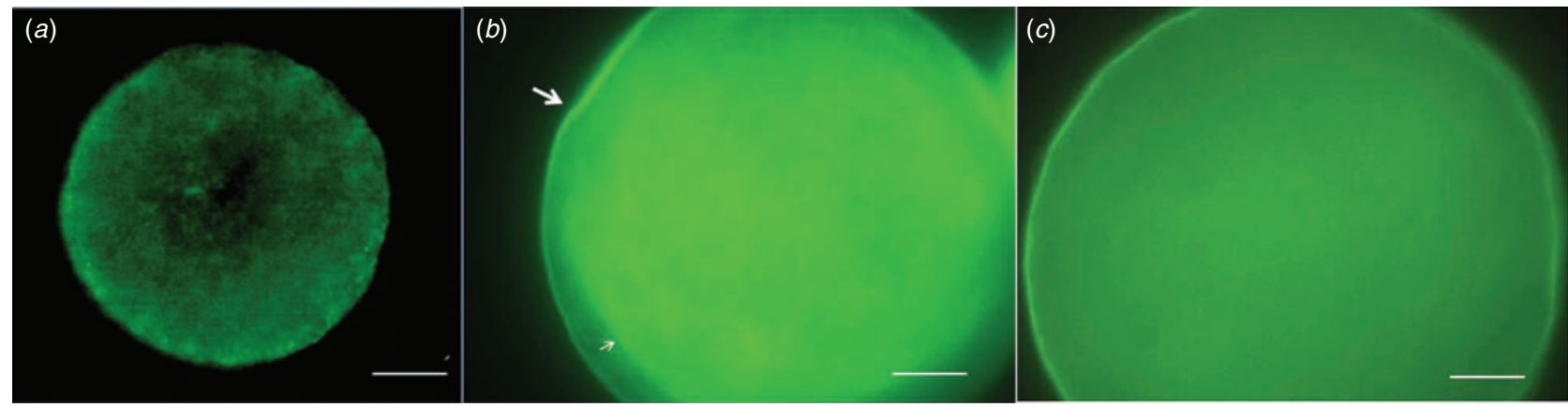

Fig. 1. Photomicrographs of canine oocytes stained with fluorescein isothiocyanate-conjugated Lens culinaris agglutinin (FITC-LCA) and Hoechst showing three patterns of cortical granule distribution. Immature; cortical granules distributed throughout the entire cytoplasm, seen as a 'cloud'. (b) In transition; peripheral (large arrow) and cytoplasmic (small arrow) cortical granule migration. (c) Mature; cortical granules distributed immediately beneath the plasma membrane and the inner part of the cytoplasm with a 'clear' aspect. Scale bar represents (a) $50 \mu \mathrm{m},(b, c) 30 \mu \mathrm{m}$.

Table 1. Meiotic status of oocytes obtained from bitches at follicular (FOL), luteal (LUT) and anoestrous (ANE) stages in vitro matured in different culture systems for $72 \mathrm{~h}$

GV, germinal vesicle; GVBD, germinal vesicle breakdown; MI, metaphase I; MII, metaphase II; D/NI, degenerated or unidentifiable oocytes. Culture systems: A, base medium (BM) $+\mathrm{hCG}+\mathrm{P} 4+\mathrm{E} 2$ continuous exposure; $\mathrm{B}$ (bi-phasic system), $\mathrm{BM}+\mathrm{hCG}$ for the first $48 \mathrm{~h}$ and $\mathrm{BM}+\mathrm{P} 4$ for additional $24 \mathrm{~h}$; $\mathrm{C}$ (bi-phasic system), $\mathrm{BM}+\mathrm{hCG}+\mathrm{P} 4+\mathrm{E} 2$ for the first $48 \mathrm{~h}$ and $\mathrm{BM}+\mathrm{P} 4$ for additional $24 \mathrm{~h}$; $\mathrm{D}, \mathrm{BM}$ without any hormonal supplementation. ${ }^{\mathrm{abc}}$ Values with different superscripts within columns are significantly different at $P<0.05$. ${ }^{A}$ Same superscript between groups indicates no significant difference

\begin{tabular}{|c|c|c|c|c|c|c|c|}
\hline \multirow[t]{2}{*}{ Group } & \multirow[t]{2}{*}{ Culture system } & \multirow[t]{2}{*}{ Oocytes $(n)$} & \multicolumn{5}{|c|}{ Meiotic status $n(\%)$} \\
\hline & & & GV & GVBD & MI & MII & $\mathrm{D} / \mathrm{NI}$ \\
\hline \multirow[t]{5}{*}{ FOL } & A & 86 & $15(17.4)^{\mathrm{a}}$ & $39(45.3)^{\mathrm{a}}$ & $14(16.4)^{\mathrm{a}}$ & $5(5.8)^{\mathrm{a}}$ & $13(15.1)^{\mathrm{a}}$ \\
\hline & $\mathrm{B}$ & 95 & $5(5.3)^{\mathrm{b}}$ & $40(42.1)^{\mathrm{a}}$ & $27(28.4)^{\mathrm{a}}$ & $19(20)^{\mathrm{b}}$ & $4(4.2)^{\mathrm{b}, \mathrm{c}}$ \\
\hline & $\mathrm{C}$ & 88 & $6(6.8)^{\mathrm{b}}$ & $39(44.3)^{\mathrm{a}}$ & $24(27.3)^{\mathrm{a}}$ & $13(14.7)^{\mathrm{a}, \mathrm{b}}$ & $6(6.8)^{\mathrm{a}, \mathrm{c}}$ \\
\hline & $\mathrm{D}$ & 75 & $29(38.7)^{\mathrm{c}}$ & $19(25.3)^{\mathrm{b}}$ & $4(5.3)^{\mathrm{b}}$ & $0^{\mathrm{c}}$ & $23(30.7)^{\mathrm{d}}$ \\
\hline & Total & 344 & $55(16)^{\mathrm{A}}$ & $137(39.8)^{\mathrm{A}}$ & $69(20.1)^{\mathrm{A}}$ & $37(10.8)^{\mathrm{A}}$ & $46(13.4)^{\mathrm{A}}$ \\
\hline \multirow[t]{5}{*}{ LUT } & A & 74 & $9(12.2)^{\mathrm{a}}$ & $30(40.5)^{\mathrm{a}}$ & $11(14.9)^{\mathrm{a}}$ & $3(4.1)^{\mathrm{a}}$ & $21(28.4)^{\mathrm{a}}$ \\
\hline & B & 90 & $6(6.7)^{a}$ & $37(41.1)^{\mathrm{a}}$ & $24(26.7)^{\mathrm{a}, \mathrm{b}}$ & $14(15.6)^{b}$ & $9(9.9)^{\mathrm{b}}$ \\
\hline & $\mathrm{C}$ & 89 & $4(4.5)^{\mathrm{a}}$ & $34(38.2)^{\mathrm{a}}$ & $26(29.2)^{\mathrm{b}}$ & $11(12.4)^{\mathrm{a}, \mathrm{b}}$ & $14(15.7)^{\mathrm{a}, \mathrm{b}}$ \\
\hline & $\mathrm{D}$ & 68 & $22(32.3)^{\mathrm{b}}$ & $10(14.7)^{\mathrm{b}}$ & $2(3)^{\mathrm{c}}$ & $0^{\mathrm{a}, \mathrm{c}}$ & $34(50)^{\mathrm{c}}$ \\
\hline & Total & 321 & $41(12.8)^{\mathrm{A}}$ & $111(34.6)^{\mathrm{A}}$ & $63(19.6)^{\mathrm{A}}$ & $28(8.7)^{\mathrm{A}}$ & $78(24.3)^{\mathrm{A}}$ \\
\hline \multirow[t]{5}{*}{ ANE } & A & 91 & $18(19.8)^{\mathrm{a}}$ & $40(43.9)^{\mathrm{a}}$ & $12(13.2)^{\mathrm{a}}$ & $3(3.3)^{\mathrm{a}}$ & $18(19.8)^{\mathrm{a}}$ \\
\hline & $\mathrm{B}$ & 120 & $8(6.7)^{\mathrm{b}}$ & $50(41.7)^{\mathrm{a}}$ & $33(27.5)^{\mathrm{b}}$ & $14(11.7)^{\mathrm{b}}$ & $15(12.5)^{\mathrm{a}}$ \\
\hline & $\mathrm{C}$ & 124 & $9(7.3)^{b}$ & $57(46)^{a}$ & $36(29)^{\mathrm{b}}$ & $17(13.7)^{\mathrm{b}}$ & $5(4)^{b}$ \\
\hline & $\mathrm{D}$ & 119 & $40(33.6)^{\mathrm{c}}$ & $18(15.1)^{\mathrm{b}}$ & $3(2.5)^{\mathrm{c}}$ & $0^{\mathrm{a}}$ & $58(48.7)^{\mathrm{c}}$ \\
\hline & Total & 454 & $75(16.5)^{\mathrm{A}}$ & $165(36.3)^{\mathrm{A}}$ & $84(18.5)^{\mathrm{A}}$ & $34(7.5)^{\mathrm{A}}$ & $96(21.1)^{\mathrm{A}}$ \\
\hline
\end{tabular}

missed. For cytoplasmic maturation, only oocytes classified as GV-MII were evaluated for cortical granule distribution; those considered degenerated were excluded. Oocytes with CG distributed throughout the cytoplasm were classified as immature, with CG distributed immediately beneath the plasma membrane as mature and with CG distributed in the cytoplasm and also immediately beneath the plasma membrane as in transition (Fig. 1).

\section{Statistical analysis}

The number of oocytes reaching each stage of nuclear and cytoplasmic maturation in each group was analysed by analysis of variance (ANOVA) in a complete randomised design (CRD). The model included the main effects of culture media and stage of oestrous cycle for each stage of oocyte maturation. The proportion of oocytes with both nuclear and cytoplasmic maturation was compared among treatments by chi square test. Level of significance was set at $95 \%(P<0.05)$.

\section{Results}

A total of 1368 Grade 1 COCs were obtained from 36 bitches (12 bitches per group) and 1119 were included in this study. The remaining oocytes were broken during removal of cumulus cells and preparation of staining.

Stage of the oestrous cycle

No differences were found in GV, GVBD, MI and MII rates between the stages of the oestrous cycle (Table 1). There were 
Table 2. Meiotic status and cortical granule distribution of bitch oocytes in vitro matured in different culture systems for $72 \mathrm{~h}$ GV, germinal vesicle; GVBD, germinal vesicle breakdown; MI, metaphase I; MII, metaphase II. Culture systems: A, base medium (BM) + hCG+P4+E2 continuous exposure; $\mathrm{B}$ (bi-phasic system), BM+ hCG for the first $48 \mathrm{~h}$ and $\mathrm{BM}+\mathrm{P} 4$ for additional $24 \mathrm{~h} ; \mathrm{C}$ (bi-phasic system), $\mathrm{BM}+\mathrm{hCG}+\mathrm{P} 4+\mathrm{E} 2 \mathrm{for}$ the first $48 \mathrm{~h}$ and $\mathrm{BM}+\mathrm{P} 4$ for additional $24 \mathrm{~h} ; \mathrm{D}, \mathrm{BM}$ without any hormonal supplementation. ${ }^{\mathrm{abc}}$ Values with different superscripts within the same meiotic status and column are significantly different at $P<0.05$

\begin{tabular}{|c|c|c|c|c|c|}
\hline \multirow[t]{2}{*}{ Meiotic status } & \multirow[t]{2}{*}{ Culture system } & \multirow{2}{*}{$\begin{array}{c}\text { Number of oocytes } \\
\text { examined }\end{array}$} & \multicolumn{3}{|c|}{ Number $(\%)$ of oocytes with specified pattern of cortical granule distribution } \\
\hline & & & Immature & Transition & Mature \\
\hline \multirow[t]{4}{*}{ GV } & A & 42 & $33(78.6)^{\mathrm{a}}$ & $9(21.4)^{\mathrm{a}}$ & 0 \\
\hline & $\mathrm{B}$ & 19 & $14(73.7)^{\mathrm{a}}$ & $5(26.3)^{\mathrm{a}}$ & 0 \\
\hline & $\mathrm{C}$ & 19 & $12(63.2)^{\mathrm{a}}$ & $7(36.8)^{\mathrm{a}}$ & 0 \\
\hline & $\mathrm{D}$ & 91 & $85(93.4)^{b}$ & $6(6.6)^{\mathrm{b}}$ & 0 \\
\hline \multirow[t]{3}{*}{ GVBD } & $\mathrm{A}$ & 109 & $90(82.6)^{\mathrm{a}}$ & $19(17.4)^{\mathrm{a}}$ & 0 \\
\hline & $\mathrm{C}$ & 130 & $48(37)^{\mathrm{c}}$ & $82(63)^{\mathrm{c}}$ & 0 \\
\hline & $\mathrm{D}$ & 47 & $28(59.6)^{\mathrm{b}}$ & $19(40.4)^{\mathrm{b}}$ & 0 \\
\hline \multirow[t]{4}{*}{ MI } & A & 37 & $26(70)^{\mathrm{a}}$ & $11(30)^{\mathrm{a}}$ & $0^{\mathrm{a}}$ \\
\hline & $\mathrm{B}$ & 84 & $14(16.7)^{b}$ & $57(67.9)^{\mathrm{b}}$ & $13(15.4)^{b}$ \\
\hline & $\mathrm{C}$ & 86 & $14(16.3)^{b}$ & $65(75.6)^{b}$ & $7(8.1)^{b}$ \\
\hline & $\mathrm{D}$ & 9 & $4(44.4)^{\mathrm{a}}$ & $5(55.6)^{a, b}$ & $0^{\mathrm{a}}$ \\
\hline \multirow[t]{3}{*}{ MII } & $\mathrm{A}$ & 11 & $3(27.2)^{\mathrm{a}}$ & $4(36.4)^{\mathrm{a}}$ & $4(36.4)^{\mathrm{a}}$ \\
\hline & $\mathrm{B}$ & 47 & $0^{\mathrm{a}}$ & $12(25.5)^{\mathrm{a}}$ & $35(74.5)^{\mathrm{b}}$ \\
\hline & $\mathrm{D}$ & 0 & $0^{\mathrm{a}}$ & $0^{\mathrm{a}}$ & $0^{\mathrm{a}}$ \\
\hline
\end{tabular}

Table 3. Nuclear and cytoplasmic maturation of bitch oocytes in vitro matured in different culture systems for $72 \mathrm{~h}$

Culture systems: A, base medium (BM) $+\mathrm{hCG}+\mathrm{P} 4+\mathrm{E} 2$ continuous exposure; $\mathrm{B}$ (bi-phasic system), $\mathrm{BM}+\mathrm{hCG}$ for the first $48 \mathrm{~h}$ and $\mathrm{BM}+\mathrm{P} 4$ for additional $24 \mathrm{~h}$; $\mathrm{C}$ (bi-phasic system), $\mathrm{BM}+\mathrm{hCG}+\mathrm{P} 4+\mathrm{E} 2$ for the first $48 \mathrm{~h}$ and $\mathrm{BM}+\mathrm{P} 4$ for additional $24 \mathrm{~h}$; D, BM without any hormonal supplementation. ${ }^{\text {abc }}$ Values with different superscripts within columns are significantly different at $P<0.05$

\begin{tabular}{lccc}
\hline $\begin{array}{l}\text { Culture system } \\
\text { (no. of oocytes examined) }\end{array}$ & $\begin{array}{c}\text { Nuclear maturation } \\
n(\%)\end{array}$ & $\begin{array}{c}\text { Cytoplasmic } \\
\text { maturation }^{\mathrm{B}} \\
n(\%)\end{array}$ & $\begin{array}{c}\text { Percentage of MII oocytes } \\
\text { with mature cytoplasm }\end{array}$ \\
\hline $\mathrm{A}(n=251)$ & $11(4.4)^{\mathrm{a}}$ & $4(1.6)^{\mathrm{a}}$ & $36.4^{\mathrm{a}}$ \\
$\mathrm{B}(n=305)$ & $47(15.4)^{\mathrm{b}}$ & $35(11.5)^{\mathrm{b}}$ & $74.5^{\mathrm{b}}$ \\
$\mathrm{C}(n=301)$ & $41(13.6)^{\mathrm{b}}$ & $35(11.6)^{\mathrm{b}}$ & $85.4^{\mathrm{b}}$ \\
D $(n=262)$ & $0^{\mathrm{c}}$ & $0^{\mathrm{c}}$ & $0^{\mathrm{c}}$ \\
\hline
\end{tabular}

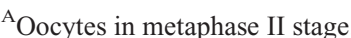

${ }^{\mathrm{B}}$ Oocytes with cortical distribution in the periphery of the oolemma.

also no differences between the stages of the oestrous cycle with regards to $\mathrm{CG}$ distribution and so data in Table 2 are grouped by meiotic status to better compare results.

\section{Effect of culture system on meiotic maturation and cortical granule distribution}

As shown in Table 1, no significant difference was noticed in GVBD rates between oocytes cultured in bi-phasic Systems B and $\mathrm{C}$ compared with the traditional medium with hormones (System A), but all three were significantly different from System D $(P<0.01)$, which had no hormonal supplementation. Bi-phasic Systems B and C yielded higher MII rates compared with Systems A and D, regardless of the stage of the oestrous cycle. There was no difference between bi-phasic Systems B and $\mathrm{C}$ with regards to $\mathrm{GV}, \mathrm{GVBD}, \mathrm{MI}$ and $\mathrm{MII}$ rates $(P>0.05)$.
The changes in cortical granule distribution and nuclei of oocytes cultured in four different media are shown in Table 2. The majority of oocytes with nuclei in GV showed granules distributed throughout the cytoplasm, irrespective of the culture media. Cortical granule migration was achieved in significantly higher rates in MII oocytes cultured in Systems B and C compared with Systems A and D. Interestingly, some oocytes cultured in Systems B and C with nuclei in MI showed a mature pattern of cortical granule distribution; no similar finding was noticed in Systems A and D.

There was a positive effect of bi-phasic Systems B and C on maturation (nuclear and cytoplasmic), in which higher rates of oocytes presented a meiotic stage of MII and a mature pattern of cortical granule distribution (74.5\% and 85.4\%) compared with Systems A and D (36.4\% and $0 \%, P<0.0001$; Table 3). 


\section{Discussion}

Previous studies on canine oocytes investigated the effects of varying the supplementation of culture media over the course of the maturation period, i.e. using so-called sequential or bi-phasic media. De los Reyes et al. (2005) reported that oocytes cultured for $48 \mathrm{~h}$ in a medium containing hCG and for the subsequent 24 or $48 \mathrm{~h}$ in a medium without this hormone presented greater percentages at MII (43.4\%) stage. Concordant with this, Hanna et al. (2008) observed higher MI-MII rates (51.3\%) when oocytes were initially matured in a medium containing meiosis blocker (roscovitine) and subsequently oestradiol and equine chorionic gonadotrophin. In turn, Alhaider and Watson (2009) used a biphasic system with decreasing concentrations of hCG in a medium containing a combination of growth factors and reported that the maturation rates were lower (12\%) than those of oocytes that were matured only in a medium containing growth factors (49\%).

Going beyond these findings, it was sought here to make novel use of bi-phasic media containing gonadotrophin (hCG) and steroids (E2 and P4) for maturation of canine oocytes obtained from bitches under different reproductive status and cultured for $72 \mathrm{~h}$. The oocytes cultured for $48 \mathrm{~h}$ with hCG (biphasic System B) or with hCG, P4 and E2 (bi-phasic System C) and for an additional $24 \mathrm{~h}$ with $\mathrm{P} 4$ presented maturation rates that were greater than those cultured with continuous hormonal exposure or without hormones.

Discrepant results from using different concentrations of hormones in in vitro cultures have already been found. Kim et al. (2005) evaluated the effect of adding P4 and E2 to the culture medium at the concentration of $2 \mu \mathrm{g} \mathrm{mL}^{-1}$ and found that this supplementation had a positive effect (16.6\% at MII), in comparison with the media that contained only one of these hormones. Vannucchi et al. (2009) supplemented the culture medium with high doses of P4 and E2 $\left(20 \mu \mathrm{g} \mathrm{mL}^{-1}\right)$ and observed significant differences in the $\mathrm{E} 2+\mathrm{P} 4$ group, in relation to the GVBD rate. In the present study, the steroid concentrations used were the same as in our other study $\left(1 \mu \mathrm{g} \mathrm{mL}^{-1}\right.$; Apparicio et al. 2011), although the hormone supplementation was performed differently in Systems B and C in order to mimic the in vivo environment. The maturation rates (MII) obtained in the bi-phasic systems were consistent with those reported in the literature. Although they were lower than expected, they were still higher than those reported by Evecen et al. (2011) who also used a sequential medium with gonadotrophins and steroids ( $20 \%$ vs $5.5 \%)$. These differences could be attributed to the distinct base medium used in each study (synthetic oviduct fluid + BSA vs medium $199+$ FBS) and also to the differences between laboratory conditions.

The sequential Systems B and C also showed a positive effect in relation to the distribution of cortical granules and their relationship with nuclear maturation. Although most of the oocytes at GVBD and MI presented cortical granules distributed both in the cytoplasm and in the periphery of the oocyte, some oocytes at MI presented cortical granules distributed at the periphery of the oocyte, which is a sign of cytoplasmic maturation. This distribution pattern was only observed in oocytes that were matured in sequential media. As far as we know, this is the first time that oocytes at MI have been observed with this type of cortical granule distribution in the bitch after IVM; a similar finding has been reported for porcine (Wang et al. 1997; Takano et al. 2002) and equine oocytes (Carneiro et al. 2002), species in which cortical granules move to the cytoplasm immediately beneath the plasma membrane in MI stage. In our previous study (Apparicio et al. 2011), only the oocytes at MII presented cytoplasmic maturation. Although the number at MII that was found previously was too low to allow a reliable comparison, we believe that the percentage of MII oocytes presenting cortical granules distributed in the periphery as a sign of cytoplasmic maturation in the present study in both bi-phasic systems $(74.5 \%$ and $85.4 \%$ for culture System B and C, respectively) ratifies the beneficial effect of the sequential systems used here. Moreover, as the migration of cortical granules is considered an important step in cytoplasmic maturation, it is possible that the limited success of bitch IVM and IVF may be due in part to an imbalanced co-ordination of nuclear and cytoplasmic maturation and, if so, the use of bi-phasic systems represents a prospective approach.

The influence of the stage of bitches' oestrous cycle on the maturation rate is still a matter of controversy and has been the focus of several studies. Yamada et al. (1993) reported that greater proportions of the oocytes obtained from females stimulated by exogenous gonadotrophins reached MII than of those obtained from females that were in anoestrus. In turn, Luvoni et al. (2001) reported that oocytes recovered from females in proestrus presented higher maturation rates than shown by oocytes from females in anoestrus. However, Hewitt and England (1997), de Ávila Rodrigues and Rodrigues (2003) and Apparicio et al. (2011) showed that the in vivo hormonal environment did not affect subsequent in vitro maturation.

In the present study, we had expected that the reproductive condition would influence how oocytes would behave in relation to the four culture media. However, the maturation rates were very similar between the groups, and there was no significant difference. Thus, our data show that the reproductive condition of the donor female is not the main factor relating to the meiotic potential of the oocyte.

In conclusion, our results demonstrated that using a bi-phasic system involving hCG, progesterone and oestradiol was beneficial in relation to meiotic competence and cortical granule distribution even though there was a lack of synchronism between nuclear and cytoplasmic maturation after $72 \mathrm{~h}$ of culture. Moreover, the phase of the oestrous cycle did not influence the nuclear and cytoplasmic maturation rates.

Within this context, it is evident that any change made to the culture medium in relation to supplementation and its concentrations may be either beneficial or harmful to the development of oocytes. Therefore, it is clearly necessary to study different concentrations and associations of hormones, along with variations in the length of exposure of the oocytes to these hormones. Moreover, our results confirm that there is a need to take into account both nuclear and cytoplasmic maturation in order to assess the efficiency of the culture media.

\section{Acknowledgements}

This research was supported by grants of Fundação de Amparo à Pesquisa do Estado de São Paulo (FAPESP), Brazil, proc. 06/51943-9 and 08/50580-5. 


\section{References}

Alhaider, A. K., and Watson, P. F. (2009). The effects of hCG and growth factors on in vitro nuclear maturation of dog oocytes obtained during anoestrus. Reprod. Fertil. Dev. 21, 538-548. doi:10.1071/RD08167

Apparicio, M., Mostachio, G. Q., Motheo, T. F., Pires-Butler, E. A., Luvoni, G. C., and Vicente, W. R. R. (2009). In vitro maturation of canine oocytes in a bi-phasic system using gonadotrophin and steroids. In '6th EVSSAR Annual Symposium, Wroclaw, (Poland)'. (Ed(s) T. Rijsselaere and W. Nizanski.) p. 57. (Wydanie pierwsze: Wydawska.)

Apparicio, M., Alves, A. E., Pires-Butler, E. A., Ribeiro, A. P. C., Covizzi, G. J., and Vicente, W. R. R. (2011). Effects of hormonal supplementation on nuclear maturation and cortical granule distribution of canine oocytes during various reproductive stages. Reprod. Domest. Anim. 46, 896-903. doi:10.1111/J.1439-0531.2011.01761.X

Carneiro, G. F., Liu, I. K. M., Hyde, D., Anderson, G. B., Lorenzo, P. L., and Ball, B. A. (2002). Quantification and distribution of equine oocyte cortical granules during meiotic maturation and after activation. Mol. Reprod. Dev. 63, 451-458. doi:10.1002/MRD.10198

Cran, D. G., and Esper, C. R. (1990). Cortical granules and the cortical reaction in mammals. J. Reprod. Fertil. Suppl. 42, 177-188.

de Ávila Rodrigues, B. A., and Rodrigues, J. L. (2003). Influence of reproductive status on in vitro oocyte maturation in dogs. Theriogenology 60, 59-66. doi:10.1016/S0093-691X(02)01301-8

De los Reyes, M., de Lange, J., Miranda, P., Palominos, J., and Barros, C. (2005). Effect of human chorionic gonadotrophin supplementation during different culture periods on in vitro maturation of canine oocytes. Theriogenology 64, 1-11. doi:10.1016/J.THERIOGENOLOGY.2004. 11.008

Evecen, M., Cirit, U., Demir, K., Hamzaoglu, A. I., Bak/rer, I., Pabuccuoglu, S., and Birler, S. (2011). Adding hormones sequentially could be an effective approach for IVM of dog oocytes. Theriogenology 75, 1647-1651. doi:10.1016/J.THERIOGENOLOGY.2011.01.004

Feldman, E., and Nelson, R. (1996) Canine female reproduction. In 'Canine and Feline Endocrinology and Reproduction'. (Eds E. Feldman and R. Nelson.) pp. 526-546. (WB Saunders Company: Philadelphia.)

Hanna, C., Menges, S., Kraemer, D., and Long, C. R. (2008). Synchronisation of canine germinal vesicle stage oocytes prior to in vitro maturation alters the kinetics of nuclear progression during subsequent resumption of meiosis. Reprod. Fertil. Dev. 20, 606-614. doi:10.1071/RD07227

Hewitt, D. A., and England, G. C. (1997). The effect of preovulatory endocrine events upon maturation of oocytes of domestic bitch. J. Reprod. Fertil. Suppl. 51, 83-91.

Kim, M. K., Fibrianto, Y. H., Goo Jang, H. J. O., Kim, H. J., Lee, K. S., Kang, S. K., Lee, B. C., and Hwang, W. S. (2005). Effects of oestradiol$17 \beta$ and progesterone supplementation on in vitro nuclear maturation of canine oocytes. Theriogenology 63, 1342-1353. doi:10.1016/ J.THERIOGENOLOGY 2004.07.019
Liu, X. Y., Mal, S. F., Miao, D. Q., Liu, D. J., Bao, S., and Tan, J. H. (2005). Cortical granules behave differently in mouse oocytes matured under different conditions. Hum. Reprod. 20, 3402-3413. doi:10.1093/ HUMREP/DEI265

Luvoni, G. C., Luciano, A. M., Modina, S., and Gandolfi, F. (2001). Influence of different stages of the oestrous cycle on cumulus-oocyte communications in canine oocytes: effects on the efficiency of in vitro maturation. J. Reprod. Fertil. Suppl. 57, 141-146.

Luvoni, G. C., Chigioni, S., Allievi, E., and Macis, D. (2005) Factors involved in vivo and in vitro maturation of canine oocytes Theriogenology 63, 41-59. doi:10.1016/J.THERIOGENOLOGY. 2004.03.004

Otoi, T., Ooka, A., Murakami, M., Kurniani Karja, M. W., and Suzuki, T. (2001). Size distribution and meiotic competence of oocytes obtained from bitch ovaries at various stages of the oestrous cycle. Reprod. Fertil. Dev. 13, 151-155. doi:10.1071/RD00098

Padilha, L. C., Teixeira, P. P. M., Pires-Butler, E. A., Apparicio, M., Motheo, T. F., Savi, P. A. P., Nakaghi, E. Y. O., Alves, A. E., and Vicente, W. R. R. (2014). In vitro maturation of oocytes from Santa Ines ewes subjected to consecutive sessions of follicular aspiration by laparoscopy. Reprod. Domest. Anim. 49(2), 243-248. doi:10.1111/RDA.12261

Takano, H., Kanda, P., and Niimura, S. (2002). The relationship between nuclear maturation and cortical granule distribution in cultured porcine oocytes. J. Mamm. Ova Res. 19, 21-25. doi:10.1274/JMOR.19.21

Tsutsui, T. (1989). Gamete physiology and timing of ovulation and fertilisation in dogs. J. Reprod. Fertil. Suppl. 39, 269-275.

Vannucchi, C. I., Faustino, M., Marques, M. G., Nichi, M., Assumpção, M. E., and Visintin, J. A. (2009). Effects of gonadotrophin-exposed medium with high concentrations of progesterone and oestradiol-17beta on in vitro maturation of canine oocytes. In Vitro Cell. Dev. Biol. Anim. 45, 328-333. doi:10.1007/S11626-009-9185-6

de Lesegno, C. V., Reynaud, K., Pechoux, C., Thoumire, S., and Chastant-Maillard, S. (2008). Ultrastructure of canine oocytes during in vivo maturation. Mol. Reprod. Dev. 75, 115-125. doi:10.1002/ MRD. 20763

Wang, W. H., Sun, Q. Y., Hosoe, M., Shioya, Y., and Day, B. N. (1997) Quantified analysis of cortical granule distribution and exocytosis of porcine oocytes during meiotic maturation and activation. Biol. Reprod. 56, 1376-1382. doi:10.1095/BIOLREPROD56.6.1376

Willingham-Rocky, L. A., Hinrichs, K., Westhusin, M. E., and Kraemer, D. C. (2003). Effects of stage of oestrous cycle and progesterone supplementation during culture on maturation of canine oocytes in vitro. Reproduction 126, 501-508. doi:10.1530/REP.0.1260501

Yamada, S., Shimazu, Y., Kawao, Y., Nakazawa, M., Naito, K., and Toyoda, Y. (1993). In vitro maturation and fertilisation of preovulatory dog oocytes. J. Reprod. Fertil. Suppl. 47, 227-229. 